\title{
Anatomical brain connectivity and positive symptoms of schizophrenia: a diffusion tensor imaging study
}

Citation for published version (APA):

Rotarska-Jagiela, A., Oertel-Knoechel, V., de Martino, F., van de Ven, V. G., Formisano, E., Roebroeck, A. F., Rami, A., Schoenmeyer, R., Haenschel, C., Hendler, T., Maurer, K., Vogeley, K., \& Linden, D. E. (2009). Anatomical brain connectivity and positive symptoms of schizophrenia: a diffusion tensor imaging study. Psychiatry Research, 174(1), 9-16. https://doi.org/10.1016/j.pscychresns.2009.03.002

Document status and date:

Published: 01/01/2009

DOI:

10.1016/j.pscychresns.2009.03.002

Document Version:

Publisher's PDF, also known as Version of record

Document license:

Taverne

Please check the document version of this publication:

- A submitted manuscript is the version of the article upon submission and before peer-review. There can be important differences between the submitted version and the official published version of record.

People interested in the research are advised to contact the author for the final version of the publication, or visit the DOI to the publisher's website.

- The final author version and the galley proof are versions of the publication after peer review.

- The final published version features the final layout of the paper including the volume, issue and page numbers.

Link to publication

\footnotetext{
General rights Owners
rights.

- You may freely distribute the URL identifying the publication in the public portal. please follow below link for the End User Agreement:

www.umlib.nl/taverne-license

Take down policy

If you believe that this document breaches copyright please contact us at:

repository@maastrichtuniversity.nl

providing details and we will investigate your claim.
}

Copyright and moral rights for the publications made accessible in the public portal are retained by the authors and/or other copyright owners and it is a condition of accessing publications that users recognise and abide by the legal requirements associated with these

- Users may download and print one copy of any publication from the public portal for the purpose of private study or research.

- You may not further distribute the material or use it for any profit-making activity or commercial gain

If the publication is distributed under the terms of Article $25 \mathrm{fa}$ of the Dutch Copyright Act, indicated by the "Taverne" license above, 


\title{
Anatomical brain connectivity and positive symptoms of schizophrenia: A diffusion tensor imaging study
}

\author{
Anna Rotarska-Jagiela, ${ }^{\mathrm{a}, \mathrm{b}, \mathrm{d}, *},{ }$, Viola Oertel-Knoechel ${ }^{\mathrm{d}}$, Federico DeMartino ${ }^{\mathrm{e}}$, Vincent van de Ven ${ }^{\mathrm{e}}$, \\ Elia Formisano ${ }^{\mathrm{e}}$, Alard Roebroeck ${ }^{\mathrm{e}}$, Abdelhaq Rami ${ }^{\mathrm{c}}$, Ralf Schoenmeyer ${ }^{\mathrm{d}}$, Corinna Haenschel ${ }^{\mathrm{d}}$, \\ Talma Hendler ${ }^{\mathrm{f}}$, Konrad Maurer ${ }^{\mathrm{d}}$, Kai Vogeley ${ }^{\mathrm{b}}$, David E.J. Linden ${ }^{\mathrm{d}, \mathrm{g}}$ \\ ${ }^{a}$ Max Planck Institute for Brain Research, Department of Neurophysiology, Deutschordenstr. 46, 60528 Frankfurt a.M., Germany \\ ${ }^{\mathrm{b}}$ Department of Psychiatry and Psychotherapy, University of Cologne, Kerpener Str. 62, 50924 Cologne, Germany \\ ${ }^{c}$ Department of Anatomy III, Johann Wolfgang Goethe University, Theodor-Stern-Kai 7, 60590 Frankfurt/Main, Germany \\ ${ }^{\mathrm{d}}$ Department of Psychiatry, Neurophysiology and Neuroimaging Lab, Johann Wolfgang Goethe University, Heinrich-Hoffman-Str. 10, 60538 Frankfurt/Main, Germany \\ 'Department of Cognitive Neuroscience, University of Maastricht, P.O. Box 616, 6200 MD Maastricht, The Netherlands \\ ${ }^{\mathrm{f}}$ Functional Brain Imaging Unit, Wohl Institute for Advanced Imaging, Tel Aviv Sourasky Medical Center, 6 Weizmann St., Tel Aviv 69978, Israel \\ ${ }^{\mathrm{g}}$ School of Psychology, University of Wales Bangor, Adeilad Brigantia, Penrallt Road, Gwynedd LL57 2AS, United Kingdom
}

\section{A R T I C L E I N F O}

\section{Article history:}

Received 20 June 2008

Received in revised form 11 October 2008

Accepted 6 March 2009

\section{Keywords:}

Diffusion Tensor Imaging

Anatomical connectivity

Hallucinations

Schizophrenia

White matter

\begin{abstract}
A B S T R A C T
Structural brain changes in schizophrenia are well documented in the neuroimaging literature. The classical morphometric analyses of magnetic resonance imaging (MRI) data have recently been supplemented by diffusion tensor imaging (DTI), which mainly assesses changes in white matter (WM). DTI increasingly provides evidence for abnormal anatomical connectivity in schizophrenia, most often using fractional anisotropy (FA) as an indicator of the integrity of WM tracts. To better understand the clinical significance of such anatomical changes, we studied FA values in a whole-brain analysis comparing paranoid schizophrenic patients with a history of auditory hallucinations and matched healthy controls. The relationship of WM changes to psychopathology was assessed by correlating FA values with PANSS scores (positive symptoms and severity of auditory hallucinations) and with illness duration. Schizophrenic patients showed FA reductions indicating WM integrity disturbance in the prefrontal regions, external capsule, pyramidal tract, occipitofrontal fasciculus, superior and inferior longitudinal fasciculi, and corpus callosum. The arcuate fasciculus was the only tract which showed increased FA values in patients. Increased FA values in this region correlated with increased severity of auditory hallucinations and length of illness. Our results suggest that local changes in anatomical integrity of WM tracts in schizophrenia may be related to patients' clinical presentation.
\end{abstract}

(c) 2009 Elsevier Ireland Ltd. All rights reserved.

\section{Introduction}

Most of the previous diffusion tensor imaging (DTI) examinations of white matter (WM) integrity in schizophrenia have reported decreased fractional anisotropy (FA) values in patients in the frontal (Kumra et al., 2004; Wolkin et al., 2003) and occipital lobes (Agartz et al., 2001; Kumra et al., 2004), and fiber tracts of the uncinate fasciculus (Burns et al., 2003; Kubicki et al., 2002b), cingulum (Kubicki et al., 2003) and corpus callosum (Foong et al., 2000b; RotarskaJagiela et al., 2008). These findings are commonly interpreted as evidence for anatomical dis- or hypo-connectivity. So far, only two studies have reported increased FA values in schizophrenia patients. In the first study, Hubl et al. (2004) found that patients with a history of auditory hallucinations had higher FA values in the arcuate fasciculus

\footnotetext{
* Corresponding author. Max Planck Institute for Brain Research, Deutschordenstr. 46, 60528 Frankfurt a.M., Germany. Tel.: +4969 6301 83782; fax: +496963013833. E-mail address: rotarska@mpih-frankfurt.mpg.de (A. Rotarska-Jagiela).
}

when compared with non-hallucinatory patients and healthy controls. A similar difference between patients with and without history of auditory hallucinations was confirmed in the second study (Shergill et al., 2007). Higher FA values in the arcuate fasciculus suggest that increased anatomical connectivity between speech and auditory areas may be neurobiologically related to the severity of auditory hallucinations (Hubl et al., 2004).

However, the association of DTI findings and the clinical presentation and length of illness is as yet poorly understood. Previous studies (Mendelsohn et al., 2006; Mitelman et al., 2007; Skelly et al., 2008; Wolkin et al., 2003) found an inverse relationship between symptom load and FA in contrast to two studies which found no significant association (Foong et al., 2000a; Minami et al., 2003). To our knowledge, only one study reported an association between FA values and increased illness duration (Mori et al., 2007). Another crosssectional examination of first-episode and chronic schizophrenia patients suggested that changes in FA may be progressive (Friedman et al., 2008). 
In the current study, we examined whether the integrity of WM fiber tracts in schizophrenic patients with a history of auditory hallucinations would correlate with the severity of positive symptoms and of acoustic hallucinations in particular. The altered connectivity, as shown by Hubl et al. (2004), may result in a predisposition for hallucinations generally, e.g. by providing a possible pathway of aberrant fronto-temporal communication. Additionally, the degree of altered connectivity may determine not just whether but also how frequently and intensely patients hear voices. To address this question, a whole-brain exploratory analysis was performed to avoid a limitation of the analyses to specific brain regions. FA values (whole-brain analyses) were correlated with positive symptom and hallucination scores as measured by the Positive and Negative Syndrome Scale (PANSS) and with duration of illness in a group of 24 patients with paranoid schizophrenia and a history of auditory hallucinations. Based on the previous literature, we hypothesized that patients would have overall decreased FA values indicating a reduced integrity of fiber tracts and hence a disturbed anatomical connectivity as compared to controls. Secondly, because all our patients had a history of acoustic hallucinations, an increased FA in the arcuate fasciculus was expected in concordance with recent studies (Hubl et al., 2004; Shergill et al., 2007), which, however, did not show a direct correlation of FA values and symptom ratings. In addition, we predicted a positive correlation with hallucination scores in this region.

\section{Methods}

\subsection{Participants}

Twenty-four inpatients and outpatients of the Department of Psychiatry of Frankfurt University Hospital and 24 matched controls participated in the study. Only patients who met the diagnostic criteria for paranoid schizophrenia according to the DSM IV and who had a history of auditory hallucinations were included in the study. The schizophrenia and control groups were matched for age, gender, and parental years of education. In addition, for patients whose university education was interrupted by the illness, we recruited university graduate controls, assuming that education level prior to disease onset was a more valid matching criterion than years in higher education. Participants with a history of other psychiatric or

Table 1

Demographic and clinical data of study participants.

\begin{tabular}{lll}
\hline & $\begin{array}{l}\text { Schizophrenia } \\
\text { patients }\end{array}$ & Controls \\
\hline Gender (M/F) & $12 / 12$ & $12 / 12$ \\
Age (Mean \pm S.D.) & $39.00 \pm 9.35$ & $39.21 \pm 8.95$ \\
Handedness (Left/Right) & $0 / 24$ & $0 / 24$ \\
Years of education (Mean \pm S.D.)* & $13.64 \pm 3.02$ & $15.96 \pm 2.66$ \\
Parental years of education (Mean \pm S.D.) & & \\
$\quad$ Mother & $12.12 \pm 2.67$ & $12.68 \pm 3.06$ \\
Father & $12.57 \pm 2.84$ & $12.86 \pm 2.87$ \\
DSM IV diagnosis (295.30) & 24 & $\mathrm{n} / \mathrm{a}$ \\
Age at onset (Mean \pm S.D.) & $26.21 \pm 9.16$ & $\mathrm{n} / \mathrm{a}$ \\
Years of illness (Mean \pm S.D.) & $12.58 \pm 7.36$ & $\mathrm{n} / \mathrm{a}$ \\
Medication (atypical neuroleptics/typical & $16 / 1 / 6 / 1$ & $\mathrm{n} / \mathrm{a}$ \\
neuroleptics/atypical neuroleptics & & \\
neuroleptics + others/no medication) & & \\
PANSS (Mean \pm S.D.) & & $\mathrm{n} / \mathrm{a}$ \\
Total score & $58.94 \pm 14.59$ & \\
Positive & $13.95 \pm 5.12$ & \\
Hallucination & $2.92 \pm 2.04$ & \\
Negative & $14.31 \pm 5.02$ & \\
General & $28.26 \pm 9.91$ & \\
ESI (Mean \pm S.D $)^{\mathrm{a}}$ & $22.54 \pm 13.18$ & \\
\hline
\end{tabular}

a Difference significant at $P<0.01$., two-tailed. neurological disorders or drug abuse were excluded. All subjects were right-handed. The study was approved by the local ethics committee and written informed consent was obtained from all participants after the goals of the project were explained to them.

\subsection{Clinical tests}

The diagnosis of paranoid schizophrenia was confirmed with a Structured Clinical Interview (SCID I). Current psychopathology was assessed with the Positive and Negative Syndrome Scale (PANSS). Patients also completed a semi-structured interview concerning the presence, frequency and severity of the auditory hallucinations. The assessment of content and quality of hallucinatory experiences was based on the criteria of Aggernaes (1972). Control participants were also interviewed with the SCID I and II to ensure that they did not suffer from any psychiatric or personality disorder. Both patients and controls were examined with the ESI (Eppendorfer Schizophrenie Inventar) (Mass et al., 2000), which measures characteristic subjective signs and symptoms of schizophrenia. Detailed demographic and clinical data of study participants are included in Table 1.

\subsection{Magnetic resonance imaging}

Magnetic resonance imaging (MRI) was performed on a 3 Tesla Allegra system (Siemens, Erlangen, Germany). T1-weighted 3D anatomical data were acquired using an MDEFT sequence with 176 slices and $1 \times 1 \times 1 \mathrm{~mm}^{3}$ voxel size. For a DTI measurement, we used a spin-echo EPI sequence $(\mathrm{TR} / \mathrm{TE}=5400 / 80 \mathrm{~ms}, 40$ slices, $1.8 \times 1.8 \times 2 \mathrm{~mm}^{3}$ voxel size) covering the whole brain except for the temporal pole and the inferior cerebellum. Six diffusion-weighted volumes were measured in the axial plane parallel to the AC-PC line in six directions with a $b$-value $=1000 \mathrm{~s} / \mathrm{mm}^{2}$ and one T2 weighted image without diffusion weighting. The DTI measurement was acquired five times and averaged before further processing. The total scan time, which included additional measurements for resting state functional MRI (not reported), lasted approximately $40 \mathrm{~min}$.

\subsection{Image pre-processing and analysis}

To correct for eddy current distortion and motion, all diffusion images were aligned to the reference volume (first B0 image) using the FSL FDT Diffusion toolbox (www.fmrib.ox.ac.uk/fsl). Co-registration to a common MNI reference image (http://mni.mcgill.ca) and re-sampling of the data into $1 \times 1 \times 1 \mathrm{~mm}^{3}$ was performed with the FSL FLIRT toolbox using an affine 12-parameter registration with correlation ratio cost function and tri-linear interpolation (Jenkinson et al., 2002). The resulting datasets were spatially smoothed with a Gaussian kernel (full-width-at-half-maximum [FWHM] $=7 \mathrm{~mm}$ ). In-house software was used to estimate and diagonalize the diffusion tensor in each voxel. Subsequently, FA maps were calculated for all participants from the eigenvalues of the diagonalized tensor (Pierpaoli and Basser, 1996). In order to be able to identify WM tracts, the results of the analyses were transformed into Talairach space.

\subsection{Whole-brain voxel-by-voxel group comparison}

To minimize the number of statistical tests performed and to ensure that only WM voxels were included in the analysis, a WM mask was created for each participant based on a T2 image acquired during DTI measurement using BrainVoyager (http://www.brainvoyager. com) and the VMR Segmenter software (http://www.bic.uni-frankfurt.de/bv-tools). For an initial WM masking, a region-growing intensity-based thresholding segmentation implemented in BrainVoyager was used. The resulting masks were grouped to obtain an overall WM map that included only voxels classified as WM in all 


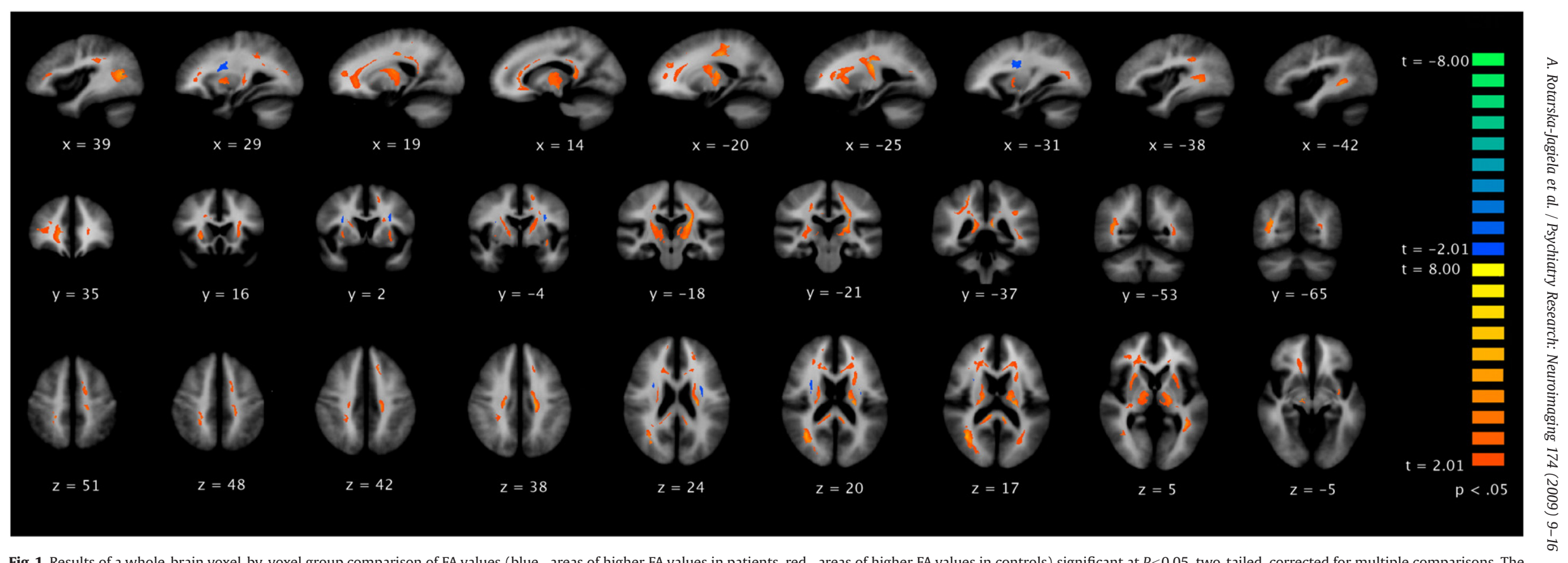

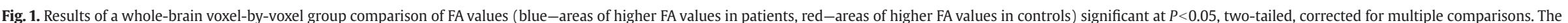
Talairach coordinates for the respective planes are indicated. (For interpretation of the references to colour in this figure legend, the reader is referred to the web version of this article.) 


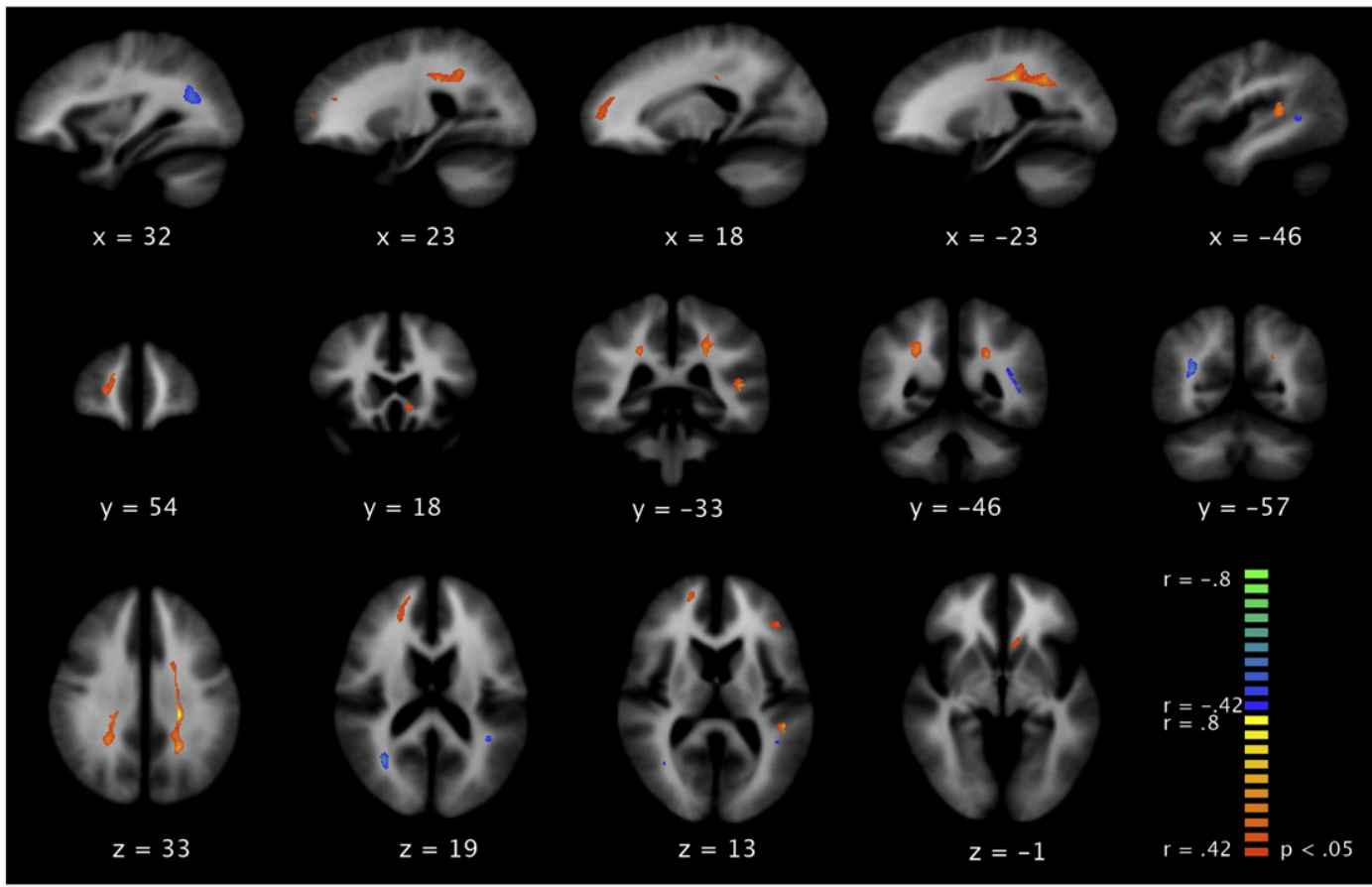

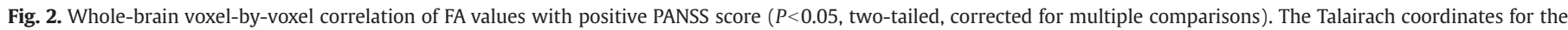
respective planes are indicated.

participants (see Figs. S1 and S2 in the online Supplementary Material for illustration of WM masking steps). A voxel-based t-test was performed only on voxels included in the final grouped WM mask. This or similar methods have been used before in other whole-brain DTI studies (Hubl et al., 2004; Medina et al., 2006; Mori et al., 2007; Shergill et al., 2007; Tuch et al., 2005). However, the very conservative masking method enabled us to examine only large WM tracts. Note that the whole basal ganglia region was included in the analysis because of inability to reliably segment WM in this area due to poor contrast of white and gray matter in this region.
2.6. Whole-brain voxel-by-voxel correlation of FA values with symptoms and years of illness

For the patient group, whole-brain voxel-by-voxel Pearson correlation coefficients were calculated between individual FA values and the PANSS scores for auditory hallucinations, between FA values and the scores for positive symptoms (with hallucination score excluded) and between FA values and years of illness. Because this comparison was calculated for the patient group only, we used the average patient WM mask.

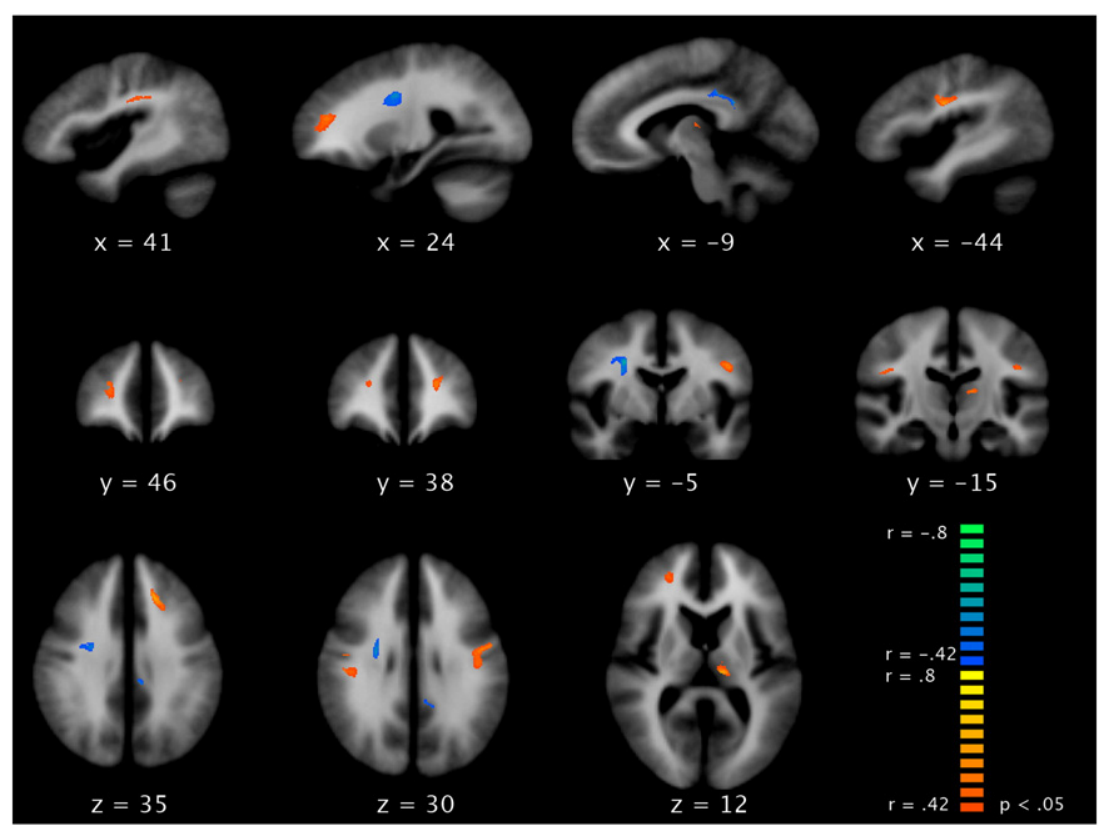

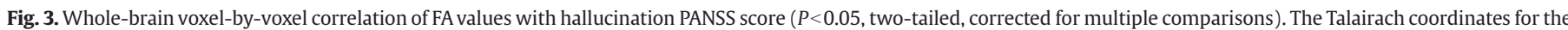
respective planes are indicated. 


\subsection{Corrections for multiple comparisons}

Correction for multiple comparisons was done using the clustersize-threshold method of Forman (Forman et al., 1995) as implemented in BrainVoyager QX (Goebel et al., 2006) and similar to other cluster-thresholding methods used in previous DTI studies (Gold et al., 2007; Medina et al., 2006; Molko et al., 2004; Salat et al., 2006; Tuch et al., 2005). In the method used herein, an initially uncorrected statistical map is used. In the second step, the statistical map's spatial smoothness was estimated. Monte Carlo simulation was used to estimate false-positive rates at a cluster level. After 1000 iterations the minimum cluster size with a cluster-level false-positive rate of $5 \%$ or less was used to threshold the statistical maps. The cluster threshold was estimated at a minimum cluster size of 150 anatomical voxels $\left(\mathrm{mm}^{3}\right)$ for the group comparison and correlation maps yielding a corrected $P$ value of 0.05 .

\section{Results}

\subsection{Behavioral and clinical data}

The control group had a significantly higher mean value of years of education (mean $=15.96$, S.D. $=2.66$ ) compared with patients (mean $=13.64$, S.D. $=3.02$ ). This result was expected since, as mentioned above, we matched the participants on the level of education rather than on the exact number of years of higher education. As an additional matching criterion, we used parental years of education, which did not significantly differ between groups (mother: mean in controls $=12.12$, S.D. $=2.67$ vs. mean in patients $=12.68$, S.D. $=3.06$; father: mean in controls $=12.57$, S.D. $=2.84$ vs. mean in patients $=12.86$, S.D. $=2.87)$. On the ESI, the controls scored significantly lower than the patients $($ mean $=4.38$, S.D. $=1.02$ vs. mean $=22.54$, S.D. $=13.18)$, which was expected based on our selection criteria for controls (no psychiatric history and no pathology on the SCID). Nine of the patients had experienced auditory hallucinations during their illness, but not within the week of the testing (PANSS score of 1 on the hallucination item), 15 patients heard voices either at the time of testing or within the week prior to the fMRI scan ( 4 received a score of 2 on the PANSS hallucination item, 3 received a score of 3 , 1 received a score of 4,3 had a score of 5,3 had a score of 6 , and 1 a score of 7). Further detailed demographic and clinical data of study participants are included in Table 1 .

\subsection{Whole-brain voxel-by-voxel group comparison}

All reported results of group comparisons were corrected for multiple comparisons at $P<0.05$ with a cluster size of at least 150 voxels using cluster-size thresholding as implemented in BrainVoyager (Forman et al., 1995). The results of the whole-brain group comparison are illustrated in Fig. 1 and summarized in Table S1 of the Supplementary Online Material with Talairach coordinates for the most significant single voxel.

Schizophrenic patients had significantly lower FA values in the right external capsule and pyramidal tract (bilaterally). Also the FA values of the corpus callosum were lower in the patient group. In addition, association fibers including left superior and bilateral inferior longitudinal fasciculi and occipitofrontal fasciculus (bilaterally) also showed lower FA values in patients. The only region with increased FA compared with controls was the arcuate fasciculus (bilaterally).

\subsection{Whole-brain voxel-by-voxel correlation of FA values with symptoms} and years of illness

The correlation maps were corrected for multiple comparisons at $P<0.05$, and a cluster size of at least 150 voxels was chosen. The results of correlations of FA values and clinical symptoms are summarized in Table S2 with Talairach coordinates for the most significant voxel, and illustrated in Figs. 2 and 3. The results of correlations of FA values and years of illness are summarized in Table S3 and illustrated in Fig. 4.

The score of the positive subscale of the PANSS correlated positively with FA values in corpus callosum, left arcuate, left superior longitudinal and bilateral occipitofrontal fasciculi and right superior frontal gyrus (Brodmann Area 9/10). FA values in the inferior longitudinal fasciculi bilaterally were negatively correlated with that scale. The hallucination subscore of the PANSS correlated positively

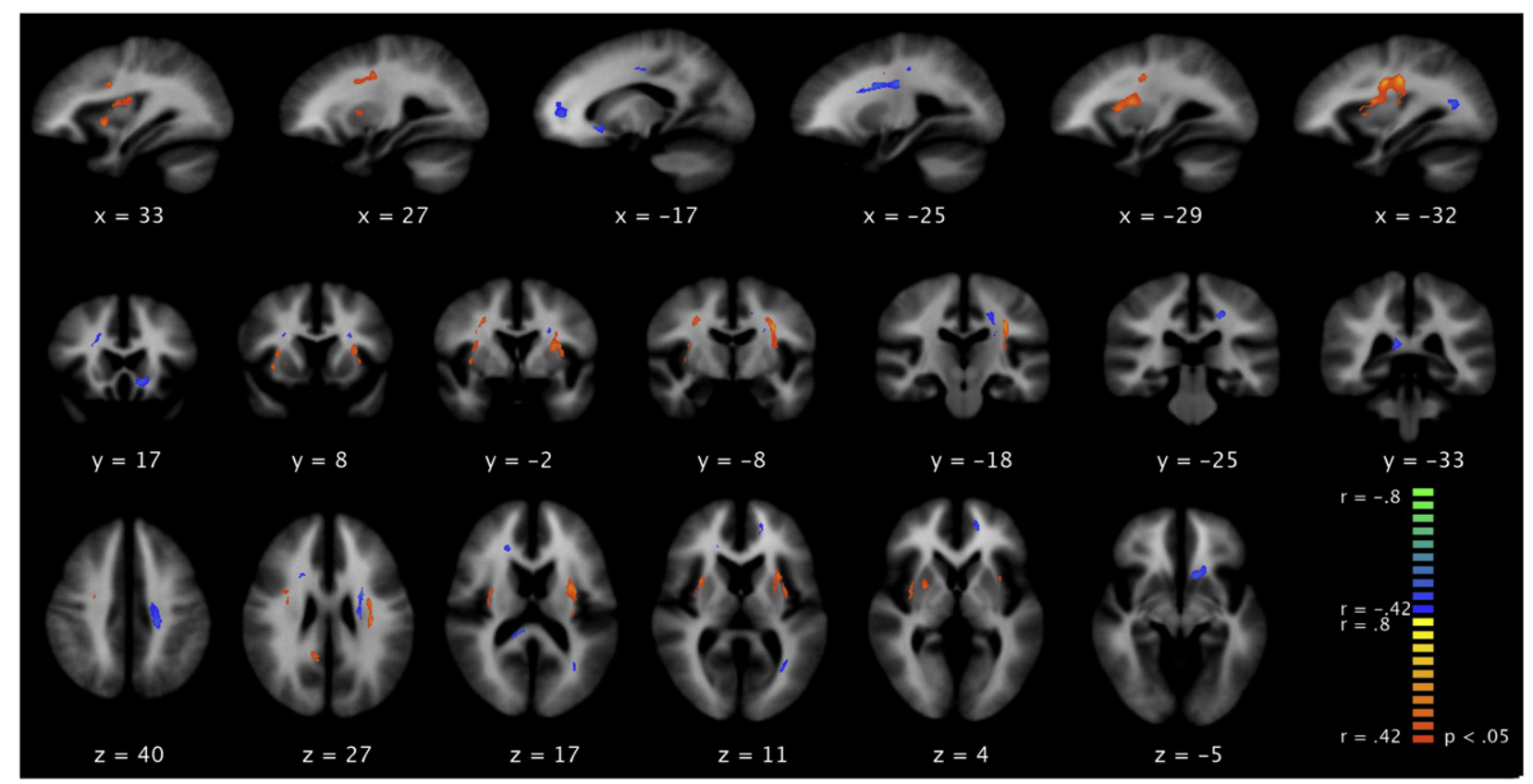

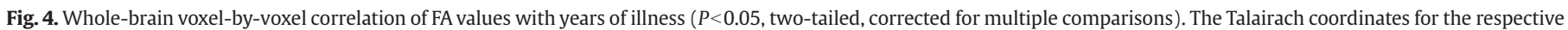
planes are indicated. 
with FA values in arcuate fasciculus bilaterally, left thalamus and prefrontal lobe (Brodmann Area 9/10) and negatively with left cingulum and right pyramidal tract.

Years of illness correlated positively with FA values in right external capsule, bilateral arcuate fasciculus and right cingulum. FA in corpus callosum, bilateral occipitofrontal fasciculus, left optic radiation and left superior frontal gyrus were inversely correlated with illness duration.

\section{Discussion}

Based on the previous literature, we hypothesized that patients would have overall decreased WM integrity as compared with controls. We also hypothesized that increased FA in the arcuate fasciculus would positively correlate with hallucinatory experiences. The results of the current study using whole-brain group comparison show a general disturbance of anatomical connectivity in schizophrenia patients. We found significant group differences in the external capsule. Only one other study examined FA values specifically in this tract (Sun et al., 2003), but it did not find statistically significant differences. However, the researchers placed regions of interest (ROIs) on only two slices, which did not overlap with clusters in our study. There are also reports of changed FA values in the uncinate fasciculus (Burns et al., 2003; Kubicki et al., 2002a), which crosses the external capsule in its most ventral section (Ebeling and von Cramon, 1992; Wakana et al., 2004). We also found changed FA values in long association fibers within the occipitofrontal fasciculus showing lower FA values in patients, as reported previously (Hubl et al., 2004). In addition, in keeping with previous studies, patients had significantly decreased FA values in the corpus callosum (Foong et al., 2000b; Rotarska-Jagiela et al., 2008) and the pyramidal tract (Agartz et al., 2001), as well as in the superior and inferior longitudinal fasciculi (Buchsbaum et al., 2006). We also found decreased FA in prefrontal regions of our patient group, replicating findings in the previous literature (Kumra et al., 2004; Wolkin et al., 2003).

As hypothesized, our sample of patients with a history of hallucinations had bilaterally increased FA values in the arcuate fasciculus, which is in concordance with previous DTI findings (Hubl et al., 2004; Shergill et al., 2007). The main finding of the present study, correlation between FA values and hallucinations in the arcuate fasciculus bilaterally, conforms to previous group comparisons between patients with and without history of hallucinations (Hubl et al., 2004; Shergill et al., 2007) but extends the earlier studies in an important way. Evidence for aberrant connectivity in patients with history of hallucinations compared with those without can be interpreted on two levels. The altered connectivity may result in a predisposition for hallucinations generally, e.g. by providing a possible pathway of aberrant fronto-temporal communication. Additionally, the degree of altered connectivity may determine not just whether but also how frequently and intensely patients hear voices. The correlation between symptom ratings and FA values with coefficients around 0.5 , amounting to about a quarter of explained variance, clearly supports this model. This hypothesis is further supported by the results of the correlation analyses of FA and years of illness, which showed a positive relationship in the regions in the proximity of the arcuate fasciculus. One possible interpretation of this finding is that the aberrant connections become stronger, the longer the patients experience auditory hallucinations, following the rules of usedependent plasticity (Hebb, 1949).

FA values are commonly interpreted as an index of anatomical connectivity with lower values indicating hypoconnectivity (Burns et al., 2003) and higher values corresponding to hyperconnectivity (Hubl et al., 2004; Shergill et al., 2007). In the following discussion we will introduce findings of functional imaging and electrophysiological studies, which provide further evidence supporting interpretation of increased FA as increased anatomical connectivity. However, other factors can influence the FA parameter, for example, loss of crossing fibers in the voxels in question (Englund et al., 2004; Larsson et al., 2004), or increased fiber diameter (Beaulieu, 2002), which may result in the same net effect of increased FA.

\subsection{Hyperconnectivity and pathophysiology of schizophrenia}

The identification of the arcuate fascicle and prefrontal WM, whose FA values were consistently correlated with the clinical scores, is compatible with the current pathophysiological models of hallucinations. Functional imaging studies showed increased co-activity during auditory hallucinations in multiple brain regions including speech production and perception areas and auditory cortex (Dierks et al., 1999; van de Ven et al., 2005), which are all anatomically connected through the arcuate fasciculus. Aberrant connections along this fiber tract, as indicated by our study, may facilitate such abnormal coactivation of language and auditory areas. Our data would thus be compatible with neuropsychological models of schizophrenia that emphasize the imbalance of activation between language production and perception areas as a possible mechanism of hallucinations (David, 2004; Woodruff, 2004).

The view that hyperconnectivity, as indexed by higher FA values, may contribute to symptom-generating neural activity is further supported by results of an electrophysiological study where longrange synchrony of the EEG was positively correlated with the PANSS hallucination score (Uhlhaas et al., 2006a). Patients with auditory hallucinations were also shown to have increased beta frequency oscillations in speech-related areas (Lee et al., 2006). Increased anatomical connectivity may facilitate spreading of oscillations between sensory areas and therefore lead to generation of neural activity resembling that produced in response to auditory stimulation (Uhlhaas and Singer, 2006).

During normal processing of self-generated speech, auditory cortex activity is inhibited by the activity of motor speech areas. This is reflected by increased gamma-band coherence during talking (Ford and Mathalon, 2005). This process, interpreted as a corollary discharge-related phenomenon, appears to be disturbed in schizophrenia patients (Heinks-Maldonado et al., 2007). Auditory hallucinations may result from a combination of increased anatomical connectivity that could facilitate a pathway through which random noise could be introduced into the speech processing system, and result in a disturbed corollary discharge. Higher noise combined with disturbed inhibition could increase the sensitivity for weak, aberrant inputs, which might subsequently result in misattribution of internally generated speech to external sources (Heinks-Maldonado et al., 2007). Excessive attention to irrelevant information could be further enhanced by decreased input from the posterior cingulate cortex, which has been shown to play a role in shifting attention away from irrelevant stimuli (Ng et al., 2007). In the present study, decreased anatomical connectivity of the posterior cingulate cortex was related to increased severity of hallucinations.

Although the results of this and previous studies provide evidence for the hyperconnectivity hypothesis of auditory hallucinations, the results pointing in the other direction should not be ignored. Previous EEG and fMRI experiments (Ford et al., 2002; Lawrie et al., 2002) have repeatedly shown that decreased functional connectivity during performance of speech and auditory tasks was related to increased severity of hallucinations. However, none of these studies directly examined functional connectivity between speech and auditory areas at the time point of actual hallucinations. Therefore, the exact relationship between disturbances in speech processing and experience of hearing voices still needs to be explored. In addition, as shown by previous DTI (Rotarska-Jagiela et al., 2008) and EEG (ffytche, 2008) examinations, hallucinations most likely result from a combination of hyper- and hypoconnectivity. Such a model receives further support from whole-brain fMRI examinations (Foucher et al., 2005). 
Decreased connectivity of the prefrontal cortex could lead to disturbances in source monitoring, which has been hypothesized to be related to hallucinatory experience (Startup et al., 2008), while increased connectivity to auditory cortex would result in the perception of voices (Dierks et al., 1999; Shergill et al., 2004). However, independent validation, e.g. through post-mortem tracer studies (Galuske et al., 2000), is needed to describe precise mechanisms influencing the observed connectivity changes.

\subsection{Hyperconnectivity and brain development in schizophrenia}

The seemingly counterintuitive findings of hyperconnectivity in schizophrenia may be explained in a neurodevelopmental context. Brain development is a complex process of establishing and pruning of axonal connections. This process is regulated by multiple factors, including sensory input, availability of neurotrophic substances, molecular markers and hormones, many of which have been found to be dysregulated in schizophrenia (Lewis and Levitt, 2002; Rapoport et al., 2005). Pruning, or elimination of transient axons, and the establishment of functional axonal contacts occur simultaneously to ensure that transient connections, which compete with functional contacts for neurotrophic factors, are eliminated (Hua and Smith, 2004). As a result, excessive pruning, which has been shown to occur in schizophrenia (Garey et al., 1998), may lead to the preservation of exuberant connections (Webster et al., 1991). This could account for the increased anatomical connectivity in the arcuate fasciculus as the results of the present study suggest.

\subsection{Future research}

The aim of future DTI research in schizophrenia should be to enhance our understanding of the relationship between psychopathology, disturbances of cognitive abilities and potential changes of neuroanatomical connectivity. DTI presently only provides information about traits rather than states. Therefore, for a deeper understanding of the pathophysiological processes that yield the phenomenology of schizophrenia, DTI should be combined with measures that directly assess neural correlates of symptoms, such as functional neuroimaging (Linden, 2006) or EEG (Uhlhaas et al., 2006b). The findings of the current study contribute to the previous literature on auditory hallucinations in schizophrenia by presenting a possible anatomical substrate for abnormal co-activation of speech and auditory areas. In analogy to the present study's focus on hallucinations, future studies might examine whether changes in specific fiber tracts are associated with different symptom dimensions and underlie the distinctive EEG patterns observed for different syndromes of schizophrenia (Lee et al., 2003). Our finding of quantitative association between altered connectivity and symptoms should also encourage research into WM changes in individuals with attenuated psychotic symptoms, e.g. as indicator of an early stage of schizophrenia, or those with varying degrees of hallucination proneness, suggesting a classification within the schizotypy continuum. Markers like the ones investigated here may then be helpful in deciding between more categorical and more dimensional approaches to psychiatric disease classification and inform about the neural basis of the putative psychosis continuum.

\section{Acknowledgments}

This study was conducted in the Frankfurt Brain Imaging Center supported by the German Ministry of Education and Research (Bundesministerium für Bildung und Forschung, BMBF) (Frankfurt, DLR 01G00203). ARJ was supported by a Josef Buchmann Doctoral Scholarship, and CH and DL received an Academic Research Collaboration grant from the German Academic Exchange Service and the British Council (no. 1229).
We thank Peter J. Uhlhaas, Max Planck Institute, Frankfurt, Germany, and Katy Thornton, University of Bangor, U.K., for comments on the manuscript and Fabrizio Esposito, Armin Heinecke and Pim Pullens, Brain Innovation, Maastricht, The Netherlands, for technical help. We are especially grateful to all participants.

\section{Appendix A. Supplementary data}

Supplementary data associated with this article can be found, in the online version, at doi:10.1016/j.pscychresns.2009.03.002.

\section{References}

Agartz, I., Andersson, J.L., Skare, S., 2001. Abnormal brain white matter in schizophrenia: a diffusion tensor imaging study. Neuroreport 12, 2251-2254.

Aggernaes, A., 1972. The experienced reality of hallucinations and other psychological phenomena. An empirical analysis. Acta Psychiatrica Scandinavica 48, 220-238.

Beaulieu, C., 2002. The basis of anisotropic water diffusion in the nervous system-a technical review. NMR in Biomedicine 15, 435-455.

Buchsbaum, M.S., Schoenknecht, P., Torosjan, Y., Newmark, R., Chu, K.W., Mitelman, S., Brickman, A.M., Shihabuddin, L., Haznedar, M.M., Hazlett, E.A., Ahmed, S., Tang, C., 2006. Diffusion tensor imaging of frontal lobe white matter tracts in schizophrenia. Annals of General Psychiatry 5, 19 .

Burns, J., Job, D., Bastin, M.E., Whalley, H., Macgillivray, T., Johnstone, E.C., Lawrie, S.M., 2003. Structural disconnectivity in schizophrenia: a diffusion tensor magnetic resonance imaging study. British Journal of Psychiatry 182, 439-443.

David, A.S., 2004. The cognitive neuropsychiatry of auditory verbal hallucinations: an overview. Cognitive Neuropsychiatry 9, 107-123.

Dierks, T., Linden, D.E., Jandl, M., Formisano, E., Goebel, R., Lanfermann, H., Singer, W., 1999. Activation of Heschl's gyrus during auditory hallucinations. Neuron 22, 615-621.

Ebeling, U., von Cramon, D., 1992. Topography of the uncinate fascicle and adjacent temporal fiber tracts. Acta Neurochirurgica (Wien) 115, 143-148.

Englund, E., Sjobeck, M., Brockstedt, S., Latt, J., Larsson, E.M., 2004. Diffusion tensor MRI post mortem demonstrated cerebral white matter pathology. Journal of Neurology 251, 350-352.

ffytche, D.H., 2008. The hodology of hallucinations. Cortex 44, 1067-1083.

Foong, J., Maier, M., Barker, G.J., Brocklehurst, S., Miller, D.H., Ron, M.A., 2000a. In vivo investigation of white matter pathology in schizophrenia with magnetisation transfer imaging. Journal of Neurology, Neurosurgery and Psychiatry 68, 70-74.

Foong, J., Maier, M., Clark, C.A., Barker, G.J., Miller, D.H., Ron, M.A., 2000b. Neuropathological abnormalities of the corpus callosum in schizophrenia: a diffusion tensor imaging study. Journal of Neurology, Neurosurgery and Psychiatry $68,242-244$.

Ford, J.M., Mathalon, D.H., 2005. Corollary discharge dysfunction in schizophrenia: can it explain auditory hallucinations? International Journal of Psychophysiology 58, 179-189.

Ford, J.M., Mathalon, D.H., Whitfield, S., Faustman, W.O., Roth, W.T., 2002. Reduced communication between frontal and temporal lobes during talking in schizophrenia. Biological Psychiatry 51, 485-492.

Forman, S.D., Cohen, J.D., Fitzgerald, M., Eddy, W.F., Mintun, M.A., Noll, D.C., 1995. Improved assessment of significant activation in functional magnetic resonance imaging (fMRI): use of a cluster-size threshold. Magnetic Resonance in Medicine 33, 636-647.

Foucher, J.R., Vidailhet, P. Chanraud, S., Gounot, D., Grucker, D., Pins, D., Damsa, C. Danion, J.M., 2005. Functional integration in schizophrenia: too little or too much? Preliminary results on fMRI data. Neuroimage 26, 374-388.

Friedman, J.I., Tang, C., Carpenter, D., Buchsbaum, M., Schmeidler, J., Flanagan, L. Golembo, S., Kanellopoulou, I., Ng, J., Hof, P.R., Harvey, P.D., Tsopelas, N.D., Stewart, D., Davis, K.L., 2008. Diffusion tensor imaging findings in first-episode and chronic schizophrenia patients. American Journal of Psychiatry 165, 1024-1032.

Galuske, R.A., Schlote, W., Bratzke, H., Singer, W., 2000. Interhemispheric asymmetries of the modular structure in human temporal cortex. Science 289, 1946-1949.

Garey, L.J., Ong, W.Y., Patel, T.S., Kanani, M., Davis, A., Mortimer, A.M., Barnes, T.R., Hirsch, S.R., 1998. Reduced dendritic spine density on cerebral cortical pyramidal neurons in schizophrenia. Journal of Neurology, Neurosurgery and Psychiatry 65, 446-453.

Goebel, R., Esposito, F., Formisano, E., 2006. Analysis of functional image analysis contest (FIAC) data with brainvoyager QX: from single-subject to cortically aligned group general linear model analysis and self-organizing group independent component analysis. Human Brain Mapping 27, 392-401.

Gold, B.T., Powell, D.K., Xuan, L., Jiang, Y., Hardy, P.A., 2007. Speed of lexical decision correlates with diffusion anisotropy in left parietal and frontal white matter: evidence from diffusion tensor imaging. Neuropsychologia 45, 2439-2446.

Hebb, D.O., 1949. The Organization of Behaviour: A Neuropsychological Theory. Wiley, New York.

Heinks-Maldonado, T.H., Mathalon, D.H., Houde, J.F., Gray, M., Faustman, W.O., Ford, J.M., 2007. Relationship of imprecise corollary discharge in schizophrenia to auditory hallucinations. Archives of General Psychiatry 64, 286-296.

Hua, J.Y., Smith, S.J., 2004. Neural activity and the dynamics of central nervous system development. Nature Neuroscience 7, 327-332.

Hubl, D., Koenig, T., Strik, W., Federspiel, A., Kreis, R., Boesch, C., Maier, S.E., Schroth, G., Lovblad, K., Dierks, T., 2004. Pathways that make voices: white matter changes in auditory hallucinations. Archives of General Psychiatry 61, 658-668. 
Jenkinson, M., Bannister, P., Brady, M., Smith, S., 2002. Improved optimization for the robust and accurate linear registration and motion correction of brain images. Neuroimage 17, 825-841.

Kubicki, M., Westin, C.F., Maier, S.E., Frumin, M., Nestor, P.G., Salisbury, D.F., Kikinis, R., Jolesz, F.A., McCarley, R.W., Shenton, M.E., 2002a. Uncinate fasciculus findings in schizophrenia: a magnetic resonance diffusion tensor imaging study. American Journal of Psychiatry 159, 813-820.

Kubicki, M., Westin, C.F., Maier, S.E., Mamata, H., Frumin, M., Ersner-Hershfield, H., Kikinis, R., Jolesz, F.A., McCarley, R., Shenton, M.E., 2002b. Diffusion tensor imaging and its application to neuropsychiatric disorders. Harvard Review of Psychiatry 10, 324-336.

Kubicki, M., Westin, C.F., Nestor, P.G., Wible, C.G., Frumin, M., Maier, S.E., Kikinis, R. Jolesz, F.A., McCarley, R.W., Shenton, M.E., 2003. Cingulate fasciculus integrity disruption in schizophrenia: a magnetic resonance diffusion tensor imaging study. Biological Psychiatry 54, 1171-1180.

Kumra, S., Ashtari, M., McMeniman, M., Vogel, J., Augustin, R., Becker, D.E., Nakayama, E., Gyato, K., Kane, J.M., Lim, K., Szeszko, P., 2004. Reduced frontal white matter integrity in early-onset schizophrenia: a preliminary study. Biological Psychiatry $55,1138-1145$

Larsson, E.M., Englund, E., Sjobeck, M., Latt, J., Brockstedt, S., 2004. MRI with diffusion tensor imaging post-mortem at $3.0 \mathrm{~T}$ in a patient with frontotemporal dementia. Dementia and Geriatric Cognitive Disorders 17, 316-319.

Lawrie, S.M., Buechel, C., Whalley, H.C., Frith, C.D., Friston, K.J., Johnstone, E.C., 2002 Reduced frontotemporal functional connectivity in schizophrenia associated with auditory hallucinations. Biological Psychiatry 51, 1008-1011.

Lee, K.H., Williams, L.M., Haig, A., Gordon, E., 2003. "Gamma (40 Hz) phase synchronicity" and symptom dimensions in schizophrenia. Cognitive Neuropsychiatry $8,57-71$.

Lee, S.H., Wynn, J.K., Green, M.F., Kim, H., Lee, K.J., Nam, M., Park, J.K., Chung, Y.C., 2006 Quantitative EEG and low resolution electromagnetic tomography (LORETA) imaging of patients with persistent auditory hallucinations. Schizophrenia Research 83, 111-119.

Lewis, D.A., Levitt, P., 2002. Schizophrenia as a disorder of neurodevelopment. Annual Reviews of Neuroscience 25, 409-432.

Linden, D.E., 2006. How psychotherapy changes the brain-the contribution of functional neuroimaging. Molecular Psychiatry 11, 528-538.

Mass, R., Haasen, C., Wolf, K., 2000. The Eppendorf Schizophrenia Inventory (ESI). Development and evaluation of a questionnaire for assessment of characteristic self perception of cognitive dysfunctions by schizophrenic patients. Nervenarzt 71, 885-892.

Medina, D., DeToledo-Morrell, L., Urresta, F., Gabrieli, J.D., Moseley, M., Fleischman, D. Bennett, D.A., Leurgans, S., Turner, D.A., Stebbins, G.T., 2006. White matter changes in mild cognitive impairment and $\mathrm{AD}$ : a diffusion tensor imaging study. Neurobiology of Aging 27, 663-672.

Mendelsohn, A. Strous, R.D., Bleich, M., Assaf, Y, Hendler, T, 2006. Regional axonal abnormalities in first episode schizophrenia: preliminary evidence based on high bvalue diffusion-weighted imaging. Psychiatry Research 146, 223-229.

Minami, T., Nobuhara, K., Okugawa, G., Takase, K., Yoshida, T., Sawada, S., Ha-Kawa, S., Ikeda, K., Kinoshita, T., 2003. Diffusion tensor magnetic resonance imaging of disruption of regional white matter in schizophrenia. Neuropsychobiology 47, 141-145.

Mitelman, S.A., Torosjan, Y., Newmark, R.E., Schneiderman, J.S., Chu, K.W., Brickman, A. M., Haznedar, M.M., Hazlett, E.A., Tang C.Y., Shihabuddin, L., Buchsbaum, M.S., 2007. Internal capsule, corpus callosum and long associative fibers in good and poor outcome schizophrenia: a diffusion tensor imaging survey. Schizophrenia Research 92, 211-224.

Molko, N., Cachia, A., Riviere, D., Mangin, J.F., Bruandet, M., LeBihan, D., Cohen, L., Dehaene, S., 2004. Brain anatomy in Turner syndrome: evidence for impaired social and spatial-numerical networks. Cerebral Cortex 14, 840-850.
Mori, T., Ohnishi, T., Hashimoto, R., Nemoto, K., Moriguchi, Y., Noguchi, H., Nakabayashi, T., Hori, H., Harada, S., Saitoh, O., Matsuda, H., Kunugi, H., 2007. Progressive changes of white matter integrity in schizophrenia revealed by diffusion tensor imaging. Psychiatry Research 154, 133-145.

Ng, C.W., Noblejas, M.I., Rodefer, J.S., Smith, C.B., Poremba, A., 2007. Double dissociation of attentional resources: prefrontal versus cingulate cortices. Journal of Neuroscience $27,12123-12131$.

Pierpaoli, C., Basser, P.J., 1996. Toward a quantitative assessment of diffusion anisotropy. Magnetuc Resonance in Medicine 36, 893-906.

Rapoport, J.L., Addington, A.M., Frangou, S., Psych, M.R., 2005. The neurodevelopmenta model of schizophrenia: update 2005. Molecular Psychiatry 10, 434-449.

Rotarska-Jagiela, A., Schonmeyer, R., Oertel, V., Haenschel, C., Vogeley, K., Linden, D.E. 2008. The corpus callosum in schizophrenia-volume and connectivity changes affect specific regions. Neuroimage 39, 1522-1532.

Salat, D.H., Smith, E.E., Tuch, D.S., Benner, T., Pappu, V., Schwab, K.M., Gurol, M.E., Rosas, H.D., Rosand, J., Greenberg, S.M., 2006. White matter alterations in cerebral amyloid angiopathy measured by diffusion tensor imaging. Stroke 37, 1759-1764.

Shergill, S.S., Brammer, M.J., Amaro, E., Williams, S.C., Murray, R.M., McGuire, P.K., 2004 Temporal course of auditory hallucinations. British Journal of Psychiatry 185, 516-517.

Shergill, S.S., Kanaan, R.A., Chitnis, X.A., O'Daly, O., Jones, D.K., Frangou, S., Williams, S.C. Howard, R.J., Barker, G.J., Murray, R.M., McGuire, P., 2007. A diffusion tensor imaging study of fasciculi in schizophrenia. American Journal of Psychiatry 164, 467-473.

Skelly, L.R., Calhoun, V., Meda, S.A., Kim, J., Mathalon, D.H., Pearlson, G.D., 2008 Diffusion tensor imaging in schizophrenia: relationship to symptoms. Schizophrenia Research 98, 157-162.

Startup, M., Startup, S., Sedgman, A., 2008. Immediate source-monitoring, self-focused attention and the positive symptoms of schizophrenia. Behavior Research and Therapy 46, 1176-1180.

Sun, Z. Wang, F., Cui, L., Breeze, J. Du, X., Wang, X Cong Z, Zhang H., Li, B., Hong, N Zhang, D., 2003. Abnormal anterior cingulum in patients with schizophrenia: diffusion tensor imaging study. Neuroreport 14, 1833-1836.

Tuch, D.S., Salat, D.H., Wisco, J.J., Zaleta, A.K., Hevelone, N.D., Rosas, H.D., 2005. Choice reaction time performance correlates with diffusion anisotropy in white matter pathways supporting visuospatial attention. Proceedings of the National Academy of Sciences of United States of America 102, 12212-12217.

Uhlhaas, P.J., Singer, W., 2006. Neural synchrony in brain disorders: relevance for cognitive dysfunctions and pathophysiology. Neuron 52, 155-168.

Uhlhaas, P.J., Linden, D.E., Singer, W., Haenschel, C., Lindner, M., Maurer, K., Rodriguez, E., 2006a. Dysfunctional long-range coordination of neural activity during Gestalt perception in schizophrenia. Journal of Neuroscience 26, 8168-8175.

Uhlhaas, P.J., Phillips, W.A., Mitchell, G., Silverstein, S.M., 2006b. Perceptual grouping in disorganized schizophrenia. Psychiatry Research 145, 105-117.

van de Ven, V.G., Formisano, E., Roder, C.H., Prvulovic, D., Bittner, R.A., Dietz, M.G., Hubl, D. Dierks, T., Federspiel, A., Esposito, F., Di Salle, F., Jansma, B., Goebel, R., Linden, D.E., 2005. The spatiotemporal pattern of auditory cortical responses during verbal hallucinations. Neuroimage 27, 644-655.

Wakana, S., Jiang, H., Nagae-Poetscher, L.M., van Zijl, P.C., Mori, S., 2004. Fiber tractbased atlas of human white matter anatomy. Radiology 230, 77-87.

Webster, M.J., Ungerleider, L.G., Bachevalier, J., 1991. Lesions of inferior temporal area TE in infant monkeys alter cortico-amygdalar projections. Neuroreport 2, 769-772.

Wolkin, A., Choi, S.J., Szilagyi, S., Sanfilipo, M., Rotrosen, J.P., Lim, K.O., 2003. Inferior frontal white matter anisotropy and negative symptoms of schizophrenia: a diffusion tensor imaging study. American Journal of Psychiatry 160, 572-574.

Woodruff, P.W., 2004. Auditory hallucinations: insights and questions from neuroimaging. Cognitive Neuropsychiatry 9, 73-91. 